\title{
Counselling as an Enabling Tool for Quality Human Development: Challenges to Childhood Growth and Cognitive Development in the $21^{\text {st }}$ Century
}

\author{
Florence Abiola Olorunfemi-Olabisi (Ph.D.) \\ Olufunmilayo Tayo-Olajubutu (Ph.D.) \\ Faculty of Education, Adekunle Ajasin University \\ Akungba-Akoko, Ondo State, Nigeria.
}

Doi:10.5901/mjss.2013.v4n3p317

\begin{abstract}
This paper examined the concept of childhood growth and cognitive development. It emphasizes on the processes of child growth and the stages of cognitive development as propagated by Piaget. The four stages of development were briefly discussed which are sensory-motor, pre-operational, concrete operational and formal- operational stages. Cognitive development at the concrete operational stage which was the main focus of this study was emphasized on. This stage coincides with the development of children at the primary school (7-12 years). There is need for educationist, to understand these process of growth and development at this stage in other to enhance the knowledge of the child through his/ her actions and behaviors. The roles of counseling as an effective and enabling tool for quality growth and development were highlighted. Factors detrimental to teaching and learning of the child were reviewed and techniques of ameliorating their effects by counseling were mentioned. Recommendation on the importance of counseling in enhancing quality human growth and intellectual development, especially at the childhood stage of life was made.
\end{abstract}

Keywords: Childhood, Growth, Development, Cognitive, Concrete-operational.

\section{Introduction}

Human development describes changes that take place in organism over the life span. Human development can be broken into different aspects. According to Woolfolk and Nicolich (1980) physical development deals with changes in the body, cognitive development refers to changes in the way a person thinks, social development talks about changes in the way an individual relates to others while personal development is the term generally used for changes in an individual personality. It refers to qualitative and quantitative changes that integrate complex structures and functions.

Human development is a pattern of movement or changes that begins at conception and continues through the human life span (Santrock, 2007). Human development and growth have been broadly divided into three stages namely childhood, adolescent and adulthood. Thus, the childhood stage lasts from birth to about 12 years. The first 12 years of the human organism is further subdivided into the following sub-stages: infancy, early childhood, middle childhood, and late childhood. The roles of counseling in fostering development at these three stages cannot be over emphasized. The focus of this paper is growth and cognitive development of the child during late-childhood (7-12years).

Human development can be broken into different aspects. According to Woolfolk and Nicolich (1980) physical development deals with changes in the body, cognitive development refers to changes in the way a person thinks, social development talks about changes in the way an individual relates to others while personal development is the term generally used for changes in an individual personality.

\subsection{Infancy (Birth-2years)}

The childhood stage of human development starts at the point when a child is born. The newly born baby is called Neonate. The first two years of human existence is referred to as infancy stage. The infancy period is a time of extraordinary rapid growth and achievement in all areas of development. Growth occurs fast during the infancy period.

The direction of growth has been described as a cephalocaundal, and proximodistal progression as well as mass to specific action. Cephalocaundal progression involves movements developing from the head to the toes through the head, the shoulder, abdomen and finally the legs and feet. Proximodistal progression on the other hand involves 
movement or growth (motor-ability) developing from the central axis of the body to the peripheral of the body, such that the shoulder and temple develop first before the arms and legs. Mass to specific movement implies that the infant baby first actions are usually global or mass before differentiating slowly. In fact the ability to make specific responses emerges after about one year.

\subsection{Early childhood}

This stage of human development ranges between 2-5 years. This stage is called pre-school stage by some development experts. In fact, Sigmud Freud, a renowned psychologist postulates that human personality and all its principles have been reached as soon as the individual is five years old. At this stage of human development, the individual is capable of physical, social, emotional, and mental development. The child learns to relate emotionally with parents, siblings and other people; while some rely on adults and accept help passively. The physical, psychological, emotional, cognitive and social developments of the child at these stages are primarily the responsibility of the parents. Language is mostly developed during the pre-school years. The parents provide the necessary and informal guidance to ensure the orderly development of the child.

\subsection{Middle Childhood}

The middle childhood refers to children ranging between ages 5-9, depending on the level of development. The middle childhood refers to children at between elementary one and three. More social and cognitive development of children takes place at this stage.

From age four to five the child learns to cooperate with friends and resist parental demands and adults dominations. Piaget description of the child's progression from solitary activities to parallel play and finally to social play is relevant to an understanding of social development (Adeniyi, 2002). According to Olorunfemi (2004), the early period of life are the formative years of the individual. Thus the type of stimulation received by the child at this period is very significant to his personality. The growth and development of the child is so critical that a defect in personality is traceable to the early period of life. Children in the mid childhood are in the process of becoming physically, socially, mentally, and emotionally developed. This developmental difference creates adjustment problem both in the tasks of school and social life.

Age six to eleven coincides with the primary school period. Children enroll in the primary schools from the age of six years in Nigeria. The primary school last for six years, thus, a child spends his late childhood in this system. Of great significance at these stages of the child's life is the demand for increase competence in the use of the intellectual, language and other skills related to learning.

Okon (1984) suggested that children should be provided with counseling service to assist them foster their self actualization. This indicates that counseling will be needed at any phase of life to enhance personal development.

Shertzer and Stone (1980) defined counseling as an applied art that seeks deliberately to change the behavior of an individual. It is a learning process in which individual learn about themselves, their personal relationship, and behavior that advance their personal development. It focuses on helping the individual to cope with developmental task such as self-definition or self- concept, self- actualization self- directive, self-control and self- monitoring. Attention is thus given to clarify the individual assets, skills, potentials, strength, and personal resources as well as weakness.

Counseling as one of the services in the guidance programme, involve a cluster of specialized activities including the information service, educational service, appraisal service, referral service, follow- up service and placement service.

The above mentioned services aimed at furnishing the individual with information about himself and world around him and also to provide a conducive environment for the individual to direct himself in solving social, educational, emotional, and personal problems. The central concern of counselling is to assist the individual in the process of selfactualization.

\section{Theory of Cognitive Development}

Cognition refers to knowing and cognitive development involves changes in the process involved in the acquisition and use of knowledge. This involves the ability to overcome difficulties in a new situation (Santrock, 2007).

Oladele (1989) viewed cognition as the growth shown by human beings as they progress from a state of not knowing to knowing. This indicates that mental process is the way by which knowledge is acquired and utilized. 
Jean Piaget $(1970,1983)$ developed a model describing how humans make sense of their world by gathering and structuring information from the environment in which they live. His theory offers a good example of the cognitive structural approach mentioned above. According to Piaget, a person's mental tools are the internal processes that each person uses to perceive and structure reality. The reality of a child may not be necessarily the same as an adult because these internal processes are subject to changes (Kagu, 2002). Gadner (1978) stated that in the field of cognitive development, there are two major approaches to explaining changes in human thinking processes. Firstly, the cognitive structural approach which places emphasis on internal changes in thinking process. Secondly, the learning environmental approach which stressed that changes in the environment as well as different experiences lead to different ways of thinking and thus, shape individual in predictable ways.

Piaget identifies four stages of cognitive development marked by fundamental different modes of thinking through which youngsters evolve. The four stages of development are: sensory-motor (0-2 years) Pre-operational (2-7years) concrete operational (7-11 years) and formal operational (12years and above). For each, he has provided a description of the cognitive activity that characterized the child and the processes that seem to underline them, and the role they play in future development.

\subsection{Sensory-motor Stage (0-2 years)}

This covers the period between birth to two years. This stage is characterized by coordinating one sensory organ with another. For example seeing and grasping. The infant begins to realize that objects do not seize to exist. Also from birth, the child passes through discrete and progressive stages of cognitive development, each of which enables him to adapt more effectively to his environment.

\subsection{Preoperational Stage (2-7years)}

This stage is called the preoperational because the child does not yet comprehend certain rules or operations. Piaget believes that this stage marks the beginning of the use of symbol to dominate the development of intellectual ability. He noted that as the use of language increases, children begin to attach new meanings to the stimuli in their environment and to use one stimulus to stand as a symbol for another. Piaget also stressed that the child develops intuitive understanding by age four, with more elaborate concepts based on the evidence of the sense (Kagan and Havenmann,1980). The child also demonstrates egocentricisms as he is unable to see the world from anyone else point of view and believes that everything centers on himlher.

\subsection{Concrete Operational Period (7-11) Years}

The development of mental operations marks the beginning of the concrete operational period which usually lasts from about age 7- 11 years. Piaget called this stage concrete operation because children can perform operations only on images of tangible objects and actual events. Among the operations that children master during this stage according to Piaget are irreversibility and decentration. Reversibility permits a child to mentally undo an action; while decentration allows the child to focus on more than one feature of a problem simultaneously. Therefore, the new found ability to coordinate several aspects of a problem help the child appreciate that there are several ways to look at things. At the concrete developmental stage which is the main focus of this study, the child has greater ability to reason and think objectively and flexibly. He thinks in concrete terms, understands what he can see and feel, Money (2006). The basic characteristics of concrete operational stage are that; the student requires:

a. The logical stability of the physical world;

b. The fact that element can be changed or transformed and still conserve many of their original characteristics; and c. sees that this change can be reversed. The children can also seriate objects according to increasing or decreasing sizes and classify object according to their shapes and colors.

Piaget believes that during this stage, the child is unable to handle abstract concept and give full performance to concrete objects. Thus, he becomes able to associate with the things and events in his environment.

\section{Educational Programme}

There is no doubt that a lot of primary school children undergoing childhood education today have emotional disturbances requiring professional help. According to Odediran (2000) these emotional problem include inability to learn, inability to 
maintain one's self as a result of health factor and inability to meet with the needs and expectations of the society.

Watkins (2000) affirmed that education should provide children with opportunities to develop optimum levels of competence for social and economic participation in their society as well as for self-fulfillment.

However, a number of barriers inhibit the opportunity for children to benefit from education as a means of developing their cognition and fulfilling their potentials. The right to education remains for too many children and unreliable goal. Recent research UNICEF (2002) affirmed that one hundred and twenty one million children lack access to education. It stated the very minimal aspiration of achieving access to basic education for all children by 2015 as unlikely to be met. Certain groups of children are disproportionately excluded from realizing their rights to education; girls continue to have less access than boys to education in many parts of the world. Thus, access to education is widely accepted as essential for the fulfillment of developing cognition and potential. UNICEF (2002) cast interesting light on the impact of poverty and inequality on the realization of a child's educational potential.

The social and economic status of parents is an indicator of educational achievement of the child. Despite widely differing educational systems, factors relating to the background of families rather than the schooling system determine educational outcomes. Better resources access to quality pre-school environment and better schools, combined with better health and higher parental and teacher expectations combine to provide a formidable advantage for children from more privileged backgrounds. Violence by teachers is one of the major contributory factors discouraging school attendances in some countries.

Children cannot learn effectively in abusive environments. Many schools are oppressive, poorly managed, inadequately resourced or offer a curriculum that is irrelevant to children's lives.

\section{Roles of Counselling}

Makinde (1987) opined that children need counseling at various level of their educational development. There is need for counseling to enable the children meet with their needs. Makinde affirmed that most of the time children feel unhappy, unable to meet their needs, confused and frustrated especially when they experience failure in their studies. Counseling helps to eliminate emotional problems which impede the child's cognitive development. In the educational development of the child, counseling will necessary be more preventive than curative. Counseling in the personal development of the child will be directed towards establishing a positive self- concept which influences academic achievement as well as intellectual development in positive ways.

Counseling at this level will focus on self- concept, self-control, self-direction development, value development and value clarification, it will ensure that the child, the teacher and the parents understand the various phases of human and individual development that facilitate rather than direct children's learning. Counseling will design situations that will let the child learn by doing to promote their thinking and discovery. To help the children by listening, watching and questioning them to attain a better understanding.

Counseling provides opportunities for children to think critically. Encourage children to think reflectively, rather than automatically accepting everything as correct. Counseling enables the teacher to be a good cognitive model to serve as an example to the students. Teachers should encourage children to collaborate with other children. Children learn not only from adults but from

other children as well.

Cross-age teaching, in which older children who are competent thinkers interact with younger children, can be especially helpful. Collaborative problem- solving teaches children how to work co-operatively with others.

Encourage the child to think freely and come up with as many different ways as possible of doing things. Don't over control by telling children precisely what to do, let their originality come.

The counselor can plan intervention that will enable the individual to slow down and consolidate growth experience. Generally counseling will be basically concerned with helping the child as a learner. It will also engage in identifying pupils and interests.

\section{Conclusion}

Cognitive development is a critical factor in human development that offers a wide challenge to teachers, parents, and guidance counselors. In view of its progressive nature from sensory-motor stage to formal-operational stage individual assimilates and accommodates experiences that lead to changes in the cognitive structure. There is a general tendency to coordinate and integrate simple phases into more complicated and sophisticated phases. To manage this phases effectively, the role of guidance and counseling in ensuring positive development of the phases and in eliminating some 
obvious obstacles or barriers that may hinder their development have also been examined. It is therefore recommended that counseling must focus on these challenges of cognitive development during childhood to enhance effective human development in the country.

\section{References}

Adeniyi,F.(2002) Geography and social development. Journal of counselling and human development, A.B.U Zaria.

Makinde, Olu (1987). Fundamental of guidance and counseling. LONDON; Macmillian Publishers Itd.

Mooney, C. G (2006). Theories of childhood. NJ. Prentice Hall

Odediran, N.O. (2000). Counselling for effective educational process, Problems and prospects. The counselor, Journal of Counselling Association of Nigeria. (18), (1) 84-90.

Okon, S.E. (1984). Guidance for the 6-3-3-4 System of education Zaria; Institute of education, Ahmadu Bello University press.

Olorunfemi, O.F (2004) Developmental psychology. Psychology of human growth and development Ikare; Amure super printers.

Piaget, J. (1952). The origin of intelligence in children.In W. Weiten (ed.) Psychology. Themes and Variations, U.S.A: Thomson Learning Inc.

Piaget, J. (1983). Piaget's Theory. In P.H.Mussen (ed.) Handbook of Child Psychology (vol.1) New York: Oxford University Press.

Santrock, J. W. (2007) Children. (Ninth edition) New York: Mc-Graw Hill Inc.

Shertzer, B. and Stone. C. (1980). Fundamental of Counselling. Boston; Houghton Muffin Company.

UNICEF (2004) the state of the world's children 2004. General SWIT: UNICEF New York.

UNICEF Innocent Research Centre (2002). Educational disadvantages in rich nations. Florence- Italy.

Watkins, K.(2000). Education now: Break the Cycle of Poverty. Oxfam, Oxford 
